University of Wollongong

Research Online

Faculty of Engineering and Information

Faculty of Engineering and Information

Sciences - Papers: Part A

Sciences

$1-1-2014$

Closure to "Active shear planes of bolted connections failing in block shear" by Drew D. A. Clements and Lip H. Teh

Drew Clements

Taylor Thomson Whitting, ddac998@uow.edu.au

Lip H. Teh

University of Wollongong, Iteh@uow.edu.au

Follow this and additional works at: https://ro.uow.edu.au/eispapers

Part of the Engineering Commons, and the Science and Technology Studies Commons

Research Online is the open access institutional repository for the University of Wollongong. For further information contact the UOW Library: research-pubs@uow.edu.au 


\title{
Closure to "Active shear planes of bolted connections failing in block shear" by Drew D. A. Clements and Lip H. Teh
}

\author{
Abstract \\ The writers thank the discusser for the interest in the original paper and for the discussion, which \\ provides the opportunity to clarify and reiterate a few points made in the original paper. The writers agree \\ with the discusser that the behavior of bolted connections is not as simple as they appear to be to the \\ casual observer, which is one reason why many structural collapses have been associated with \\ connection failures. Furthermore, a substantial number of code equations for various ultimate limit states \\ of bolted connections lead to considerable errors on either side of conservatism (Teh and Clements 2012; \\ Teh and Gilbert 2012; Teh and Yazici 2013a).

\section{Keywords} \\ block, failing, connections, bolted, planes, shear, teh, active, h, closure, lip, clements, drew \\ Disciplines \\ Engineering | Science and Technology Studies

\section{Publication Details} \\ Clements, D. D. A. \& Teh, L. H. (2014). Closure to "Active shear planes of bolted connections failing in \\ block shear" by Drew D. A. Clements and Lip H. Teh. Journal of Structural Engineering, 140 (2), \\ 07013002-1-07013002-2.
}




\title{
Closure to "Active Shear Planes of Bolted Connections Failing in Block Shear" by Drew D. A. Clements and Lip H. Teh
}

\author{
Drew D. A. Clements ${ }^{1}$ and Lip H. Teh ${ }^{2}$ A.M.ASCE
}

The authors thank the discusser for his interest in the paper and for his discussions, which provide the opportunity to clarify and reiterate a few points made in the paper.

The authors agree with the discusser that the behaviour of bolted connections is not as simple as they appear to be to the casual observer, which is one reason why many structural collapses have been associated with connection failures. Furthermore, a substantial number of code equations for various ultimate limit states of bolted connections have been demonstrated to lead to considerable errors on either side of conservatism (Teh \& Clements 2012, Teh \& Gilbert 2012, Teh \&Yazici 2013a).

The authors also agree that simplifying assumptions lead to savings in analysis time, and the finite element model should be accurate enough to provide useful results that can be interpreted to reach the correct conclusion. As stated in the paper, the aim of the finite element analysis is to confirm the location of the active shear planes indicated by the experimental evidence of Franchuk et al. (2003) and identified by Teh \& Clements (2012). These active shear planes are regions of maximum shear stresses.

However, the authors disagree with the discusser's statement that flexible solid elements should be used to model the bolts and initial bolt pretension. Firstly, whether the bolts are perfectly rigid or not does not affect the ultimate limit state of block shear failure of the bolted connections, nor the location of the active shear planes. As far as the test specimens are concerned, the high-strength steel bolts were virtually rigid, especially when compared to the connected thin sheets used in the laboratory tests, which was why each bolt was modelled as a $3 \mathrm{D}$ analytical rigid body revolved shell.

Secondly, bolt pretension should not be modelled in the analysis at all since there was no bolt pretension in the laboratory tests. The discusser is encouraged to read the referenced paper by Teh \& Clements (2012), who presented the laboratory tests, in particular the section "Specimen Configurations and Test Arrangements". It was stated that the bolts were installed by hand with minimal tightening, so there was no bolt pretension.

The "skid marks" mentioned by the discusser and apparently shown Figure 12(a) of the paper were not the result of clamped bolt heads, but due to scrubbing during the specimen fabrication. Marks almost transverse to the direction of loading can also be seen in the lower right region. The initially more flexible response shown in Figure 8 was not due to slippage of the bolted connection, but due to the slippage between the inner sheet and the shim plates used to make up the difference between the minimum jaw opening of $5.5 \mathrm{~mm}$ and the thin

\footnotetext{
${ }^{1}$ Structural Engineer, Taylor Thomson Whitting, 48 Chandos Street, St Leonards, NSW 2065, AUSTRALIA.

${ }^{2}$ Senior Lecturer, School of Civil, Mining \& Environmental Engineering, University Of Wollongong, Wollongong, NSW 2500, AUSTRALIA.
} 
sheet thickness of $3 \mathrm{~mm}$. These shim plates on both sides of the inner sheet are not shown in Figure 4 since they were not relevant to the issue of concentric loading. As stated in the section "Finite Element Analysis to Locate the Active Shear Planes", there was also flexibility or slippage in the testing system which manifested in the apparent response of the tension coupon. In any case, slip behaviour is not relevant to determining the location of the active shear planes since the load was transferred via the bolts bearing on the bolt holes.

The authors disagree with the discusser's assertion that displacements should be imposed on the inner sheet rather than the bolts. It is the relative displacement between the bolts and the clamped end of the inner sheet that matters.

The curling behaviour (out-of-plane deformation) mentioned by the discusser was not present in the laboratory tests of the specimens studied in the paper, all of which were double-shear connections as depicted in Figure 4 of the paper. As pointed out by Teh \& Gilbert (2012), the inner sheet of a double-shear connection is not subject to out-of-plane failure modes since the loading is concentric. It was for this reason that the mid-plane of the finite element model for the inner sheet was restrained from out-of-plane displacements.

The first figure provided by the discusser is for a single-shear connection, which has very different behaviour from the double-shear connections studied in the paper. The discusser is encouraged to read the first paragraph of the section "Finite Element Analysis to Locate the Active Shear Planes”, and look at Figure 4 of the paper. It was clearly stated that the finite element models simulate the concentrically loaded inner sheets of double-shear bolted connections.

The discusser is correct that the finite element analysis did not simulate fracture, because such simulation is unnecessary for determining the ultimate limit load of a specimen failing in block shear through the shear yielding and tensile rupture mechanism. As explained in the paper, the ultimate load of such a specimen is reached due to necking of the tensile net section, and before fracture. This phenomenon is indicated in Figure 8, and is particularly evident in Figure 13. The load only dropped abruptly following fracture, which took place after the limit load had passed.

The shear failure planes shown in the second figure provided by the discusser isare not correct, since it is not possible for maximum shear stresses to occur along those planes due to the bolts bearing symmetrically on the bolt holes. In fact, Figures 10 and 11 show that there are minimal if any shear stresses along the bolt centrelines, as logically expected. The use of such planes has been shown to lead to excessive conservatism against laboratory test results of the authors as well as independent test results on hot-rolled steel plate connections obtained by various researchers around the world (Teh \& Yazici 2013a).

The discusser's statement that shear fractures occur from the edge to bolt hole (AB and CD path shown in the second figure of the discusser) has confused the fracture at the edge due to tensile stresses transverse to the direction of loading to be shear fracture. Shear fracture starts from the bolt hole, not from the edge, as pointed out by Kim \& Yura (1999) and Teh \& 
Yazici (2013b). It can also be seen in Figures 10 and 11 that the shear stresses are maximum adjacent to the bolt hole, and decreases towards the edge as logically expected.

The potential misidentification of fracture at the edge due to tensile stresses transverse to the direction of loading for shear fracture had been well anticipated by Teh \& Yazici (2013b). The discusser is encouraged to read that paper and look at Figs 4(b) and (5) of Teh \& Yazici (2013b), which show tensile fracture at the edge and shear fracture at the bolt hole, respectively.

The discusser has misunderstood what in-plane shear stresses, denoted S12, are. These are in fact the shear stresses mentioned by the discusser to be parallel to the $\mathrm{AB}$ and $\mathrm{CD}$ lines (which, by the way, should be acting in pair with shear stresses perpendicular to themselves for equilibrium in the plane of the sheet, hence the designation S12). The discusser has confused the shear stresses parallel to the AB and CD lines to be S11.

In the second sentence of the second paragraph of the discusser's section "Failure Check", the discusser confuses S11 to be the normal stresses along the BC line, which are actually denoted S22 in ABAQUS. In the third sentence, however, the discusser confuses S11 to be the shear stresses along $\mathrm{AB}$ and $\mathrm{CD}$ lines, which are denoted S12 in ABAQUS.

The S11 component mentioned by the discusser actually denotes the normal stresses in the direction of the " 1 " axis, i.e. perpendicular to the direction of loading of the bolted connection specimen. These stresses reach the maximum tensile values at the edge downstream from the bolts, and can cause tensile fracture at the edge if the end distance $e_{1}$ is small enough, as pointed out by Kim \& Yura (1999). Such fracture should not be confused with shear fracture, which would be initiated adjacent to the bolt hole.

The use of effective plastic strain (PEEQ) contours by the discusser and the use of von Mises stress contours by other authors in the literature have obscured the mechanism of block shear failures, as it was very difficult if not impossible to identify the regions of maximum shear strains (or stresses) from the combined strain or stress contours. Furthermore, it is impossible to tell from the effective strain contours, which are scalar quantities, whether a particular region is subjected to tensile or compressive stresses. It was only when the in-plane shear stress contours were plotted by the authors that the regions of maximum shear stresses could be seen clearly for the specimens undergoing block shear failures.

The discusser's third figure does not appear to be connected to the topic (no pun intended), as the gusset plates can be seen to buckle under compression. Block shear failures (or the "ultimate fracture" mentioned by discusser) do not take place under such a condition.

For the purpose of determining the location of the active shear planes, which has been indicated by experimental evidence and verified against laboratory test results, there is little point in retracing the load-deflection paths. The discusser's statement that "Most of FE studies present comparisons between two results with respect to characteristic behaviour" does not provide a scientific reason for retracing the load-deflection paths in order to determine the location of the active shear planes. 
Franchuk, C. R., Driver, R. G., and Grondin, G. Y. (2003) "Experimental investigation of block shear failure in coped steel beams.” Can. J. Civ. Eng., 30, 871-881.

Kim, H. J., and Yura, J. A. (1999) "The effect of ultimate-to-yield ratio on the bearing strength of bolted connections.” J. Construct. Steel Res., 49, 255-269.

Teh, L. H., and Clements, D. D. A. (2012) "Block shear capacity of bolted connections in cold-reduced steel sheets.” J. Struct. Eng., 138 (4), 459-467.

Teh, L. H., and Gilbert, B. P. (2012) "Net section tension capacity of bolted connections in cold-reduced steel sheets,” J. Struct. Eng., 138 (3), 337-344.

Teh, L. H. and Yazici, V. (2013a) "Block shear capacity of bolted connections in hot-rolled steel plates." Connection Workshop VII, European Convention for Constructional Steelwork Task Committee 10, 91-100.

Teh, L. H., and Yazici, V. (2013b) "Unconventional block shear failures of bolted connections in cold-reduced steel sheet.” Engineering Structures, 56, 567-571. 